\title{
Tingkat Deviasi Konversi Lahan di Kawasan Lindung Kelurahan Wonorejo Surabaya
}

\author{
Tyton Rachmatullah dan Hertiari Idajati \\ Jurusan Perencanaan Wilayah dan Kota, Fakultas Teknik Sipil dan Perencanaan \\ Institut Teknologi Sepuluh Nopember (ITS) \\ Jl. Arief Rahman Hakim, Surabaya 60111 Indonesia \\ e-mail: hertiari.idajati@urplan.its.ac.id
}

\begin{abstract}
Abstrak-Perkembangan Kota Surabaya mulai mengarah ke Surabaya Timur, perkembangan yang terjadi semakin merambah pemanfaatan lahan di kawasan lindung khususnya di Kelurahan Wonorejo. Pada kelurahan ini alih fungsi yang terjadi berupa mangrove menjadi pertambakan dan pertambakan menjadi permukiman. Oleh karena itu, diperlukannya suatu upaya untuk mengetahui tingkat deviasi konversi lahan. Penelitian ini bertujuan untuk mengetahui tingkat deviasi konversi lahan di kawasan lindung Kelurahan Wonorejo. Untuk mencapai tujuan, terdapat sasaran yang akan dicapai yaitu menganalisis perubahan pemanfaatan lahan, menganalisis laju kecepatan perubahan pemanfaatan lahan, dan menganalisis persebaran dan arah perubahan pemanfaatan lahan. Hasil penelitian ini pada tahapan awal didapatkan bahwa konversi lahan yang terjadi di kawasan lindung berupa lahan mangrove, tambak, dan permukiman. Melalui analisis overlay diketahui tingkat deviasi konversi lahan pada tahun 2004-2014 termasuk pada tingkat deviasi cepat dengan mengalami penurunan luas lahan.
\end{abstract}

Kata Kunci-Kawasan Lindung, Konversi Lahan, Tingkat Deviasi.

\section{PENDAHULUAN}

$\mathrm{K}$ AWASAN lindung yang terdapat di kawasan pamurbaya sangat rentan terhadap alih fungsi lahan, hal ini ditunjukkan dengan ditemukannya patok-patok yang digunakan untuk mengavling lahan pamurbaya yang berada di sekitar pesisir kawasan lindung atau yang biasa disebut sebagai tanah oloran [1]. Kerusakan terbesar kawasan lindung berupa mangrove yang terjadi di kawasan pamurbaya terdapat di Kelurahan Wonorejo, kerusakan tersebut banyak diakibatkan oleh pembalakan liar yang dilakukan oleh warga setempat [2]. Kondisi mangrove di Kelurahan Wonorejo termasuk pada kondisi kerusakan yang paling tinggi diantara kelurahankelurahan di pamurbaya. Kondisi mangrove di Kelurahan Wonorejo $60 \%$ berkondisi baik, $38 \%$ berkondisi sedang, dan sisanya yaitu 2\% berkondisi rusak [3]. Pada tahun 2003-2013 diketahui bahwa rata-rata luas lahan mangrove yang beralih fungsi di Kelurahan Wonorejo adalah sebesar 0,44 Ha/tahun, alih fungsi yang terjadi berupa pertambakan [4].

Kelurahan Wonorejo memiliki rata-rata tingkat pertumbuhan penduduk per tahun sebesar $0,056 \%$, hal ini menunjukkan bahwa pertumbuhan penduduk per tahun di Kelurahan Wonorejo lebih tinggi dibanding dengan rata-rata pertumbuhan penduduk di Kecamatan Rungkut [5]. Dengan pertumbuhan penduduk tersebut maka akan meningkatkan kebutuhan bermukim, perkembangan permukiman yang terjadi di Kelurahan Wonorejo menjadikan munculnya perumahan baru yang berdekatan dengan kawasan konservasi mangrove wonorejo sehingga membuat kondisi lingkungan semakin buruk akibat dari sampah perumahan [6].

Berdasarkan kondisi eksisting diketahui terdapat permukiman yang berada di kawasan lindung Kelurahan Wonorejo, koordinat permukiman tersebut pada UTM WGS 49S (X 235725,41, Y 691790,98) yang merupakan koordinat yang termasuk dalam bagian kawasan lindung. Hal tersebut menyalahi RTRW Surabaya dimana pengembangan perumahan dan permukiman baru tidak diperbolehkan pada kawasan lindung [7]. Oleh karena itu, dengan semakin maraknya alih fungsi lahan di kawasan lindung yang terjadi maka diperlukannya identifikasi terhadap tingkat deviasi konversi lahan di kawasan lindung Kelurahan Wonorejo.

\section{METODE PENELITIAN}

\section{A. Kajian Pustaka}

Sebelum memasuki proses analisis dengan menggunakan teknik overlay, terlebih dahulu dilakukan kajian pustaka terkait pola perubahan pemanfaatan lahan. Tujuan dari kajian pustaka ini adalah untuk mendapatkan variabel yang kemudian akan diteliti dalam penelitian.

Tabel 1

Variabel yang diteliti dalam penelitian

\begin{tabular}{l|l}
\hline \hline \multicolumn{1}{c|}{ Kajian Teori } & \multicolumn{1}{c}{ Variabel } \\
\hline Pola Perubahan \\
Pemanfaatan Lahan & Pemanfaatan lahan mangrove \\
\cline { 2 - 2 } & Pemanfaatan lahan pertambakan \\
\cline { 2 - 2 } & Pemanfaatan lahan permukiman \\
\cline { 2 - 2 } & $\begin{array}{l}\text { Luas perubahan pemanfaatan lahan } \\
\text { mangrove, pertambakan, dan } \\
\text { permukiman }\end{array}$ \\
\cline { 2 - 2 } & $\begin{array}{l}\text { Lokasi sebaran mangrove, tambak, } \\
\text { dan permukiman }\end{array}$ \\
\hline \hline
\end{tabular}

Sumber : Hasil Sintesa Kajian Pustaka, 2015 


\section{B. Metode Pengumpulan Data}

Data yang dibutuhkan peneliti untuk mencapai tujuan dan sasaran penelitian yaitu data primer dan data sekunder. Data primer yang diperoleh melalui observasi lapangan. Sedangkan data sekunder diperoleh melalui survei instansi dan literatur yang berkaitan dengan penelitian.

\section{Analisis Tingkat Deviasi Konversi Lahan di Kawasan Lindung Kelurahan Wonorejo}

Alat yang digunakan untuk analisis ini adalah Geographic Information System (GIS). Metode analisis ini merupakan analisis secara spasial dengan menggunakan teknik Overlay. Dengan melakukan Overlay melalui software ArcGIS 10.1 ini maka nantinya akan diketahui jumlah perubahan lahan beserta pola sebaran yang terjadi di Kelurahan Wonorejo, untuk laju kecepatan perubahan dilakukan melalui analisis deskriptif kuantitatif. tahapan analisis tingkat deviasi konversi lahan di kawasan lindung Kelurahan Wonorejo,yaitu :

\section{Analisis perubahan pemanfaatan lahan}

Identifikasi perubahan lahan digunakan untuk mengetahui luas kawasan mangrove yang menjadi pertambakan dan pertambakan menjadi permukiman selama 2 periode yaitu tahun 2004-2009 (periode 1) dan 2009-2014 (periode 2).

2. Analisis laju kecepatan perubahan pemanfaatan lahan

Analisis kecepatan perubahan lahan digunakan untuk mengetahui perubahan lahan pada periode analisis. Laju kecepatan luasan perubahan lahan dengan satuan $\mathrm{Ha} /$ tahun yang akan dihitung pada periode 1 dan 2. Adapun rumus untuk mencari kecepatan perubahan penggunaan lahan adalah [8] :

$$
\begin{aligned}
& V=\frac{L}{t} \\
& \text { Dimana : } \\
& \begin{array}{ll}
V= & \text { kecepatan perubahan penggunaan lahan } \\
& \quad(\mathrm{Ha} / \mathrm{tahun})
\end{array} \\
& \begin{array}{l}
L= \\
t \quad \text { luas lahan yang mengalami perubahan }(\mathrm{Ha}) \\
\text { Keterangan : Nilai } V \text { dihitung pada tiap periode waktu }
\end{array}
\end{aligned}
$$

Dalam analisis ini, output yang dihasilkan berupa nilai laju kecepatan perubahan pemanfaatan lahan mangrove menjadi pertambakan dan pertambakan menjadi permukiman. Berikut ini merupakan parameter tingkat laju kecepatan perubahan pemanfaatan lahan.

Tabel 2.

Parameter tingkat laju kecepatan perubahan pemanfaatan lahan

\begin{tabular}{c|c}
\hline \hline Keterangan & Tingkat Kecepatan \\
\hline Vi $>$ Vrata-rata & Cepat \\
\hline Vrata-rata $>$ Vi $>0$ & Lambat \\
\hline Vi $=0$ & Tetap \\
\hline \hline
\end{tabular}

Sumber: Khairunnisa, 2010 [9]

3. Analisis persebaran dan arah perubahan pemanfaatan lahan

Analisis persebaran dan arah perubahan pemanfaatan lahan merupakan analisis spasial dengan menggunakan teknik overlay. Sehingga pada proses analisis ini akan diketahui luas perubahan pada tiap periode analisis. Hasil analisis ini berupa peta pola perubahan penggunaan lahan di Kelurahan Wonorejo.
Setelah melalui beberapa tahap overlay maka selanjutnya dilakukan perhitungan deviasi. Hasil perhitungan deviasi akan dikelompokkan, untuk mengelompokkan sesuai dengan tingkat deviasi maka digunakanlah parameter tingkat deviasi perubahan pemanfaatan lahan.

Tabel 3.

Parameter Tingkat Deviasi Perubahan Pemanfaatan Lahan

\begin{tabular}{c|c}
\hline \hline Keterangan & Tingkat Deviasi \\
\hline Vi $>$ Vrata-rata & Cepat \\
\hline Vrata-rata $>\mathrm{Vi}>0$ & Lambat \\
\hline $\mathrm{Vi}=0$ & Tetap \\
\hline \hline
\end{tabular}

Sumber: Diolah dari Khairunnisa, 2015

\section{HASIL DAN DISKUSI}

\section{A. Analisis Perubahan Pemanfaatan Lahan}

Jenis penggunaan lahan yang digunakan untuk analisis yaitu permukiman, tambak, dan mangrove di kawasan lindung pada tahun 2004, 2009, dan 2014.

Tabel 4.

Perubahan luas pemanfaatan lahan di kawasan lindung

\begin{tabular}{l|r|r|r|r|r}
\hline \hline \multirow{3}{*}{ Lahan } & \multicolumn{3}{|c|}{ Luas Eksisting } & \multicolumn{2}{c}{ Luas Perubahan (Ha) } \\
\cline { 2 - 6 } & $\mathbf{2 0 0 4}$ & \multicolumn{1}{|c|}{$\mathbf{2 0 0 9}$} & \multicolumn{1}{c|}{$\mathbf{2 0 1 4}$} & Periode 1 & \multicolumn{1}{c}{ Periode 2 } \\
\hline Mangrove & 34,36 & 22,99 & 23,05 & 11,37 & $-0,06$ \\
\hline Tambak & 284,13 & 295,51 & 291,20 & $-11,38$ & 4,31 \\
\hline Permukiman & 0 & 0 & 0,79 & 0 & $-0,79$ \\
\hline \hline
\end{tabular}

Sumber : Hasil Analisis, 2015

Keterangan : (+) Penurunan luas, (-) Penambahan luas

Pada periode 1, luas lahan mangrove di kawasan lindung mengalami penurunan sebesar 11,37 $\mathrm{Ha}$, penurunan luas lahan mangrove ini berbanding terbalik dengan bertambahnya luas lahan pertambakan yakni sebesar 11,38 Ha. Sedangkan tidak terdapat permukiman pada periode 1 .

Pada periode 2, menunjukkan pemanfaatan lahan mangrove yang mulai meningkat sebesar 0,06 Ha akibat dari program pemerintah mengenai mangrove. Sedangkan untuk lahan tambak mengalami penurunan luas sebesar 4,31 Ha, penurunan luas lahan tersebut dikarenakan pada periode 2 ini mulai terdapat permukiman di kawasan lindung.

\section{B. Analisis Laju Kecepatan Perubahan Pemanfaatan Lahan}

Berdasarkan data luas perubahan pemanfaatan lahan, analisis laju kecepatan perubahan pemanfaatan lahan dibagi menjadi 2 (dua) periode. Periode pertama tahun 2004-2009 dan periode kedua tahun 2009-2014.

Tabel 5.

Laju kecepatan perubahan pemanfaatan lahan di kawasan lindung

\begin{tabular}{l|r|r|r|r}
\hline \hline \multirow{2}{*}{ Lahan } & \multicolumn{2}{|c|}{ Luas Perubahan (Ha) } & \multicolumn{2}{c}{ Kecepatan Perubahan } \\
\cline { 2 - 5 } & Periode 1 & Periode 2 & V1 (Ha/tahun) & V2 (Ha/tahun) \\
\hline Mangrove & 11,37 & $-0,06$ & 2,27 & $-0,01$ \\
\hline Tambak & $-11,38$ & 4,31 & $-2,28$ & 0,86 \\
\hline Permukiman & 0 & $-0,79$ & 0 & $-0,16$ \\
\hline \hline
\end{tabular}

Sumber : Hasil Analisis, 2015 
Berdasarkan hasil perhitungan kecepatan perubahan pemanfaatan lahan pada tiap periode, maka dapat diketahui rata-rata laju perubahan pemanfaatan lahan. Melalui parameter tingkat laju kecepatan perubahan pemanfaatan lahan, dapat diketahui tingkat kecepatan perubahan pemanfaatan lahan.

Tabel 6.

Klasifikasi perubahan pemanfaatan lahan di kawasan lindung

\begin{tabular}{c|c}
\hline \hline Keterangan & Tingkat Kecepatan \\
\hline \multicolumn{2}{|c}{ Periode 1 (2004-2009) } \\
\hline $\mathrm{Vi}>1,52$ & Cepat \\
\hline $1,52>\mathrm{Vi}>0$ & Lambat \\
\hline $\mathrm{Vi}=0$ & Tetap \\
\hline & Cepat \\
\hline $\mathrm{Vi}>0,34$ & Lambat \\
\hline $0,34>\mathrm{Vi}>0$ & Tetap \\
\hline $\mathrm{Vi}=0$ & Periode 2 (2009-2014) \\
\hline \hline
\end{tabular}

Sumber : Hasil Analisis, 2015

Tabel 7.

Tingkat Laju Kecepatan Perubahan Pemanfaatan Lahan di Kawasan Lindung

\begin{tabular}{l|r|r|c|c}
\hline \hline \multirow{2}{*}{ Lahan } & \multicolumn{2}{|c|}{ Kecepatan Perubahan } & \multicolumn{2}{c}{ Tingkat Perubahan } \\
\cline { 2 - 5 } & $\begin{array}{c}\text { V1 } \\
\text { (Ha/Tahun) }\end{array}$ & $\begin{array}{c}\text { V2 } \\
\text { (Ha/Tahun) }\end{array}$ & $\begin{array}{c}\text { Periode } \\
\mathbf{1}\end{array}$ & $\begin{array}{c}\text { Periode } \\
\mathbf{2}\end{array}$ \\
\hline Mangrove & 2,27 & $-0,01$ & Cepat & Lambat \\
\hline Tambak & $-2,28$ & 0,86 & Cepat & Cepat \\
\hline Permukiman & 0 & $-0,16$ & Tetap & Lambat \\
\hline \hline
\end{tabular}

Sumber : Hasil Analisis, 2015

Keterangan : (+) Penurunan luas, (-) Penambahan luas

\section{Analisis Persebaran dan Arah Perubahan Pemanfaatan Lahan}

Input analisis ini adalah peta penggunaan lahan eksisting tahun 2004, 2009, dan 2014. Ketiga peta ini dibedakan berdasarkan periodenya, periode 1 tahun 2004-2009 dan periode 2 tahun 2009-2014. Kemudian peta tersebut ditumpuk untuk melihat persebaran perubahan pemanfaatan lahan di kawasan lindung Kelurahan Wonorejo.

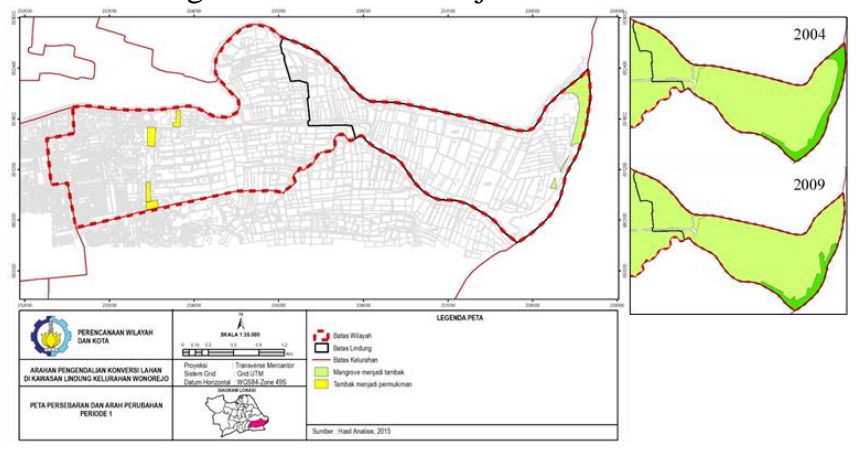

Gambar 1. Peta Persebaran dan arah perubahan periode 1

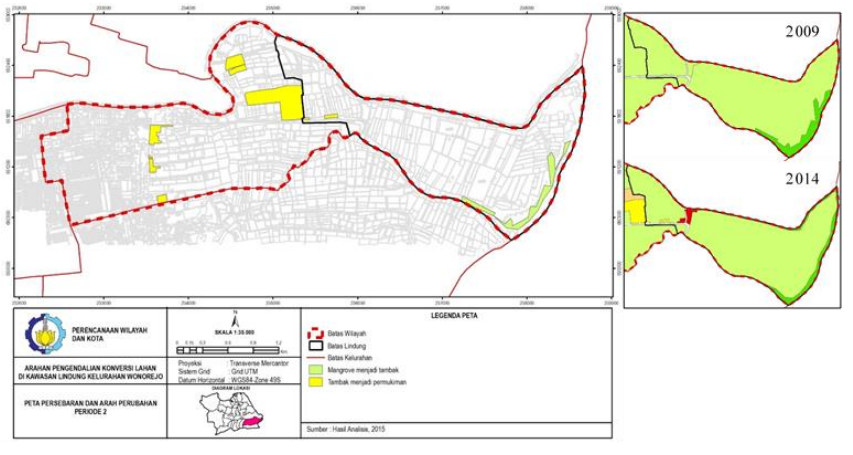

Gambar 2. Peta Persebaran dan arah perubahan periode 2

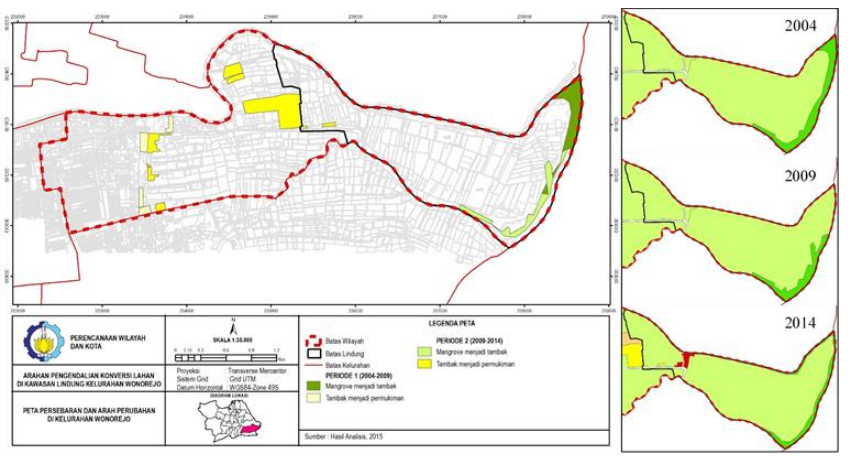

Gambar 3. Peta Persebaran dan arah perubahan di Kelurahan Wonorejo pada tahun 2004-2014

Pada peta persebaran dan arah perubahan pemanfaatan lahan menunjukkan bahwa penyimpangan perubahan pemanfaatan lahan mulai terjadi di Kelurahan Wonorejo, khususnya pada kawasan yang berada didekat batas antara kawasan lindung dan kawasan budidaya. Berdasarkan dari analisis perubahan pemanfaatan lahan, dapat diketahui bahwa perubahan pemanfaatan lahan yang terjadi berupa lahan mangrove menjadi pertambakan dan pertambakan menjadi permukiman.

Perhitungan penyimpangan atau deviasi perubahan pemanfaatan lahan yang terjadi di kawasan lindung dapat dilihat pada tabel berikut.

Tabel 8.

Deviasi perubahan pemanfaatan lahan periode 1 di kawasan lindung

\begin{tabular}{|c|c|c|c|c|}
\hline \multirow{2}{*}{ Lahan } & \multicolumn{2}{|c|}{ Tahun (Ha) } & \multirow{2}{*}{$\begin{array}{c}\text { Perubahan } \\
\text { (Ha) }\end{array}$} & \multirow{2}{*}{$\begin{array}{c}\text { Deviasi } \\
(\%)\end{array}$} \\
\hline & 2004 & 2009 & & \\
\hline Mangrove & 34,36 & 22,99 & $-11,37$ & $-49,46$ \\
\hline Tambak & 284,13 & 295,51 & 11,38 & 3,85 \\
\hline Permukiman & 0 & 0 & 0 & 0 \\
\hline
\end{tabular}

Sumber : Hasil Analisis, 2015

Keterangan : (+) Penambahan luas, (-) Penurunan luas

Tabel 9.

Deviasi perubahan pemanfaatan lahan periode 2 di kawasan lindung

\begin{tabular}{l|l|l|l} 
Lahan & Tahun (Ha) & Perubahan & Deviasi \\
\hline
\end{tabular}




\begin{tabular}{l|r|r|r|r}
\hline & \multicolumn{1}{|c|}{$\mathbf{2 0 0 9}$} & \multicolumn{1}{|c|}{$\mathbf{2 0 1 4}$} & \multicolumn{1}{c|}{ (Ha) } & \multicolumn{1}{c}{$(\boldsymbol{\%})$} \\
\hline Mangrove & 22,99 & 23,05 & 0,06 & 0,01 \\
\hline Tambak & 295,51 & 291,20 & $-4,31$ & $-12,55$ \\
\hline Permukiman & 0 & 0,79 & 0,79 & 0,01 \\
\hline \hline
\end{tabular}

Sumber : Hasil Analisis, 2015

Keterangan : (+) Penambahan luas, (-) Penurunan luas

Berdasarkan hasil perhitungan deviasi perubahan pemanfaatan lahan pada periode 1 dan 2 di kawasan lindung, menunjukkan terjadinya perubahan pemanfaatan lahan di kawasan lindung, yang semula merupakan lahan mangrove berubah menjadi lahan pertambakan dan terdapat pula lahan pertambakan yang berubah menjadi permukiman. Hal ini diikuti dengan perkembangan pemanfaatan lahan permukiman di Kelurahan Wonorejo yang mulai merambah ke kawasan lindung. Untuk lebih jelas mengenai jenis perubahan dan luas perubahan pemanfaatan lahan maka dapat dilihat pada tabel berikut.

Tabel 10. Jenis perubahan pemanfaatan lahan di kawasan lindung

\begin{tabular}{c|r|r}
\multicolumn{2}{c|}{ Jenis perubahan pemanfaatan lahan di kawasan lindung } \\
\hline \multirow{2}{*}{ Lahan } & \multicolumn{2}{|c}{ Luas Lahan (Ha) } \\
\cline { 2 - 3 } & $\begin{array}{c}\text { Periode } \\
\mathbf{1}\end{array}$ & $\begin{array}{c}\text { Periode } \\
\mathbf{2}\end{array}$ \\
\hline Mangrove menjadi tambak & 13,18 & 10,24 \\
\hline Tambak menjadi permukiman & 0 & 0,79 \\
\hline \hline
\end{tabular}

Jenis perubahan pemanfaatan lahan di kawasan lindung menunjukkan bahwa perubahan mangrove menjadi tambak cenderung menurun. Namun untuk perubahan lahan tambak menjadi permukiman cenderung mengalami peningkatan.

Tabel 11.

Tingkat deviasi perubahan pemanfaatan lahan di kawasan lindung

\begin{tabular}{l|r|r|c}
\hline \multicolumn{1}{c|}{ Lahan } & $\begin{array}{c}\text { Arah } \\
\text { Perubahan }\end{array}$ & Deviasi (\%) & Tingkat Deviasi \\
\hline \multicolumn{4}{c}{ Periode 1 (2004-2009) } \\
\hline Deviasi Kawasan Lindung (rata-rata 17,77) \\
\hline Mangrove & Penurunan & 49,46 & Cepat \\
\hline Tambak & Penambahan & 3,85 & Lambat \\
\hline Permukiman & \multicolumn{4}{c}{ Tetap } & 0 & Tetap \\
\hline \multicolumn{4}{c}{ Periode 2 (2009-2014) } \\
\hline Deviasi Kawasan Lindung (rata-rata 4,19) \\
\hline Mangrove & Penambahan & 0,01 & Lambat \\
\hline Tambak & Penurunan & 12,55 & Cepat \\
\hline Permukiman & Penambahan & 0,01 & Lambat \\
\hline \hline
\end{tabular}

Tingkat deviasi perubahan pemanfaatan lahan menunjukkan bahwa deviasi di kawasan lindung pada tiap periodenya memiliki tingkatan yang berbeda. Hasil dari analisis tingkat deviasi konversi lahan di kawasan lindung Kelurahan Wonorejo menunjukkan bahwa pada periode 1 (2004-2009) lahan mangrove termasuk pada tingkat deviasi cepat, deviasi yang terjadi yakni sebesar $49,46 \%$. Terjadinya penurunan luas lahan mangrove tersebut dikarenakan beralih fungsi menjadi lahan pertambakan. Selanjutnya pada periode 2 (2009-2014) lahan pertambakan mengalami penurunan luas lahan, yakni dengan deviasi sebesar $12,55 \%$. Lahan pertambakan yang mengalami penurunan luas tersebut diikuti dengan terjadinya penambahan luas lahan permukiman dengan deviasi $0,01 \%$ di kawasan lindung.

\section{KESIMPULAN}

Tingkat deviasi konversi lahan di kawasan lindung Kelurahan Wonorejo diperlukan untuk mengetahui deviasi atau simpangan yang terjadi di kawasan lindung Kelurahan Wonorejo. Melalui teknik analisis deskriptif kuantitatif dan analisis overlay didapatkan hasil, yaitu :

1) Periode 1 (2004-2009) lahan mangrove termasuk pada tingkat deviasi cepat. Terjadinya penurunan luas lahan mangrove tersebut dikarenakan beralih fungsi menjadi lahan pertambakan.

2) Periode 2 (2009-2014) lahan pertambakan mengalami penurunan luas lahan. Lahan pertambakan yang mengalami penurunan luas tersebut diikuti dengan terjadinya penambahan luas lahan permukiman di kawasan lindung.

\section{DAFTAR PUSTAKA}

[1] Jawapos. 2015. Pemasangan Patok di Kawasan Konservasi Pamurbaya Masih Misterius. Koran Jawapos edisi 28 Januari 2015.

[2] Harly, Priscillia. 2013. Fasilitas Edu-Wisata Pembudidayaan Mangrove Wonorejo di Surabaya. Jurnal Edimensi Arsitektur Vol. 1, No. 1-2.

[3] Pemerintah Kota Surabaya. 2013. Laporan Status Lingkungan Hidup (SLHD) Kota Surabaya Tahun 2013. Badan Lingkungan Hidup Kota Surabaya.

[4] Pradana, Putra Jaya. 2014. Arahan Pengendalian Penggunaan Lahan Berdasarkan Kemampuan Penampungan Air di Kawasan Konservasi (Studi Kasus: Pantai Timur Surabaya). ITS: Surabaya.

[5] Badan Pusat Statistik. 2013. Kecamatan Rungkut Dalam Angka. BPS Kota Surabaya.

[6] Koran-sindo.com. 2013. Dari http://www.koransindo.com/node/322688. Diakses pada tanggal 9 Oktober 2014.

[7] Pemerintah Kota Surabaya. 2014. Rencana Tata Ruang Wilayah (RTRW) Kota Surabaya Tahun 2014-2034. Bappeko Surabaya.

[8] Alfarizi, M. 2009. Arahan Pengendalian Perubahan Penggunaan Lahan Pada Kawasan Konservasi Mangrove Pantai Timur Surabaya. ITS: Surabaya.

[9] Khairunnisa. 2010. Arahan Pengendalian Konversi Hutan Mangrove di Pesisir Kabupaten Sidoarjo. ITS: Surabaya. 